\title{
Magnetic properties of surficial sediments in Lake Ogawara on the Pacific coast of northeastern Japan: spatial variability and correlation with brackish water stratification
}

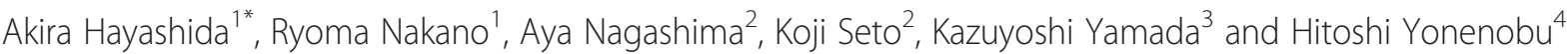

\begin{abstract}
To examine limnological conditions in Lake Ogawara on the Pacific coast of northwestern Japan, we investigated the magnetic properties of dredged bottom sediment originally collected from the lake in the summer of 2011. We used non-destructive methods to measure the low-field magnetic susceptibility shortly after sampling, and anhysteretic remanent magnetization (ARM) was assessed in 2012 and 2015. The ARM acquisition and demagnetization curves from littoral sites showed several patterns that reflect the provenance of the sediments. At water depths below $10 \mathrm{~m}$, the magnetic susceptibility and ARM of greenish black mud with high organic content decreased considerably with the increase in water depth, but ARM increased slightly at water depths greater than $16 \mathrm{~m}$. We also found that the magnetic concentrations of mud samples were reduced markedly during a period of storage for about 3 years. We attributed these reductions to diagenetic loss of magnetic minerals, which had been enhanced at deeper sites. It is possible that the ARM carriers in deeper areas were derived from authigenic formation of iron sulfide or from deposition of suspended matter in the hypolimnion water. We propose that the magnetic properties of surficial sediments are controlled by limnological stratification of the brackish lake water, thus possibly providing an analog for down-core variations of magnetic parameters associated with the modification of magnetic minerals during reductive diagenesis.
\end{abstract}

Keywords: Environmental magnetism, Lake sediment, Magnetic properties, Reductive diagenesis, Storage diagenesis

\section{Background}

Lake Ogawara is a brackish coastal lagoon on the Pacific coast of Aomori Prefecture, northwestern Japan (Fig. 1). The lake is connected to the Pacific by the Takase-gawa River and an artificial sluice (the Takase-gawa sluice). The average water depth of the lake is about $11 \mathrm{~m}$, and in the central part of the lake, the water depth ranges from 15 to $25 \mathrm{~m}$. There is a year-round halocline at 10-15 $\mathrm{m}$ depth, and the bottom to middle waters are anoxic (Fujiwara et al. 2003a). The lake basin is filled with about $20 \mathrm{~m}$ of clayey to sandy sediments that were deposited over the last 10,000 years (Inagaki et al. 2012). The sediments of Lake Ogawara, which

\footnotetext{
* Correspondence: ahay@mail.doshisha.ac.jp

${ }^{1}$ Department of Environmental Systems, Doshisha University, Kyotanabe, Kyoto 610-0321, Japan

Full list of author information is available at the end of the article
}

include a succession of finely laminated clays, represent a good natural archive of past environmental changes. Shortly after the 2011 Tohoku earthquake (the 2011 off the Pacific coast of Tohoku Earthquake), tsunami waves flooded the lake via the Takase-gawa River and sluice, which raises the possibility that the sedimentary profile there may provide evidence of past tsunamis during the Holocene.

Seto et al. (2012) carried out a systematic survey to collect lake water and bottom sediment samples in August and September 2011. Their aims were to gain an understanding of the present limnological condition of Lake Ogawara and to attempt to identify tsunami deposits in the lake. During the survey, Seto et al. (2012) identified a coarse sand layer containing molluscan shell fragments and rounded pumice grains on the floor of the Takase-gawa River channel and in the Takase-gawa 


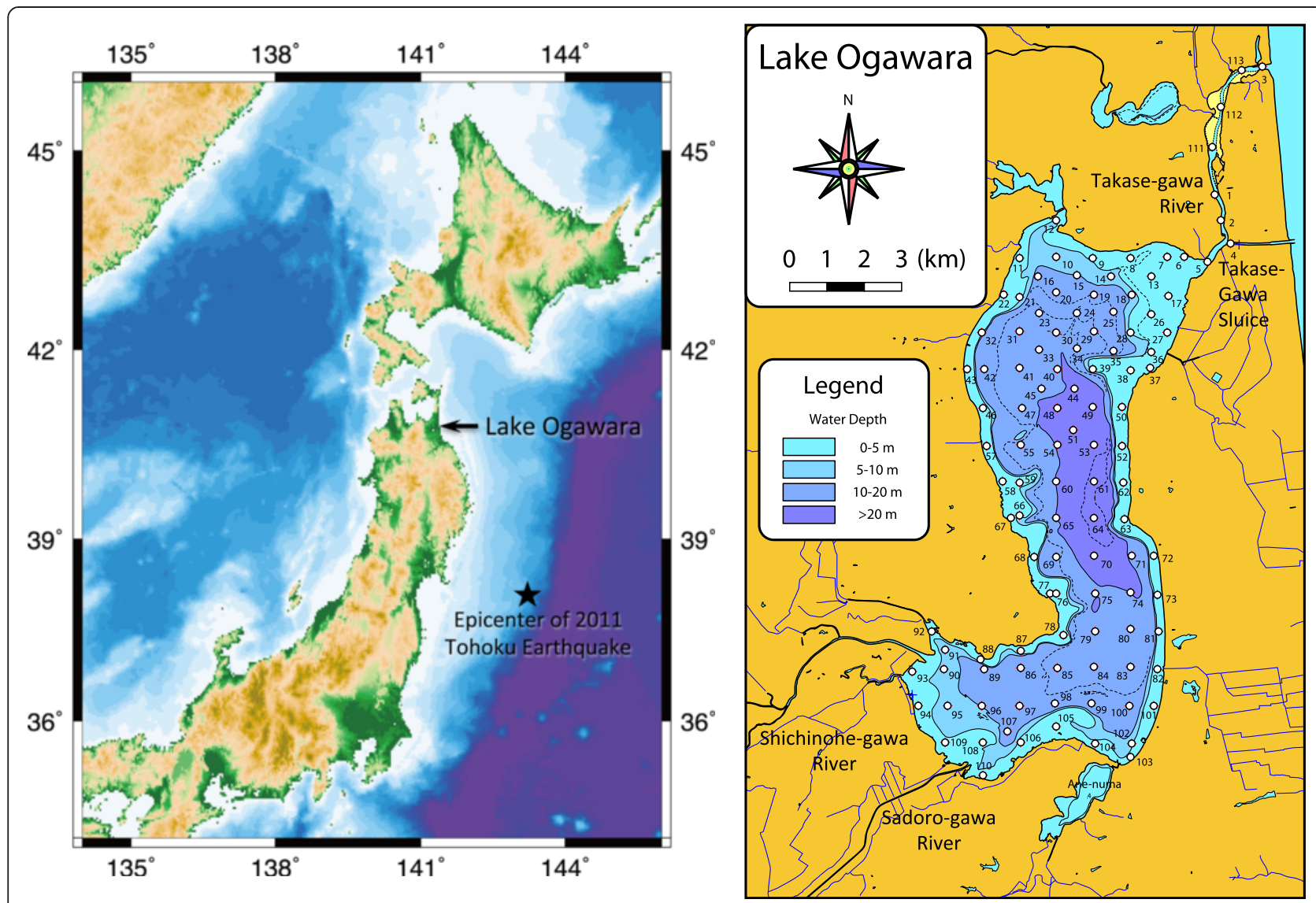

Fig. 1 Regional map showing the locations of Lake Ogawara and the epicenter of the 2011 Tohoku earthquake (left) and sampling sites for bottom sediments (right). The base map of the left panel was generated with the Generic Mapping Tools (GMT) map generator (http://woodshole.er.usgs.gov/mapit/)

sluice, which they interpreted to be sediments transported from the sandy coastal beach by the 2011 tsunami. They also found granule to coarse sand deposits along the lake coast, particularly near the Takase-gawa River (Fig. 2a), but no tsunami deposits were visually identified on the lake floor. It is possible, however, that fine-grained suspended sediments were deposited in the lake by the tsunami in March 2011.

In this paper, we describe the magnetic properties of bottom sediments dredged from Lake Ogawara, which we measured by using mainly non-destructive methods. We present spatial variations of magnetic concentration parameters including the low-field magnetic susceptibility and anhysteretic remanent magnetization (ARM). Studies of the magnetic properties of lake sediments are widely used to reconstruct the past geomagnetic field and to investigate paleoenvironments (Thompson and Oldfield 1986; Evans and Heller 2003; Liu et al. 2012). For both of these purposes, it is important to understand the origin of magnetic minerals in sediments. The sources of magnetic minerals in coastal lakes can be complicated; for example, detrital input is controlled by hydrological processes in the watershed, while authigenic mineral formation is related to the aquatic productivity of lake water, and both of these may be affected by the influx of marine water and relative sea-level changes. In addition, aeolian dust may accumulate in sediments under a certain condition (Liu et al. 2015). Magnetic measurements of surficial deposits in lakes can therefore provide useful information on modern lake sediment formation processes and can assist researchers in interpreting magnetic proxies for paleoenvironments.

Although non-destructive measurements of magnetic concentration parameters provide a quick and efficient method for characterizing sediment samples, it is generally difficult to determine magnetic mineral species by using only such measurements. We therefore attempted to estimate the magnetic coercivity distribution and blocking temperatures of isothermal remanent magnetization (IRM) on selected samples. We found, however, that magnetic concentration parameters were reduced markedly during refrigerated storage of samples for 3 years after collection, particularly in samples from the deeper part of the lake. We suggest that metastable magnetic minerals decay after sample recovery. 


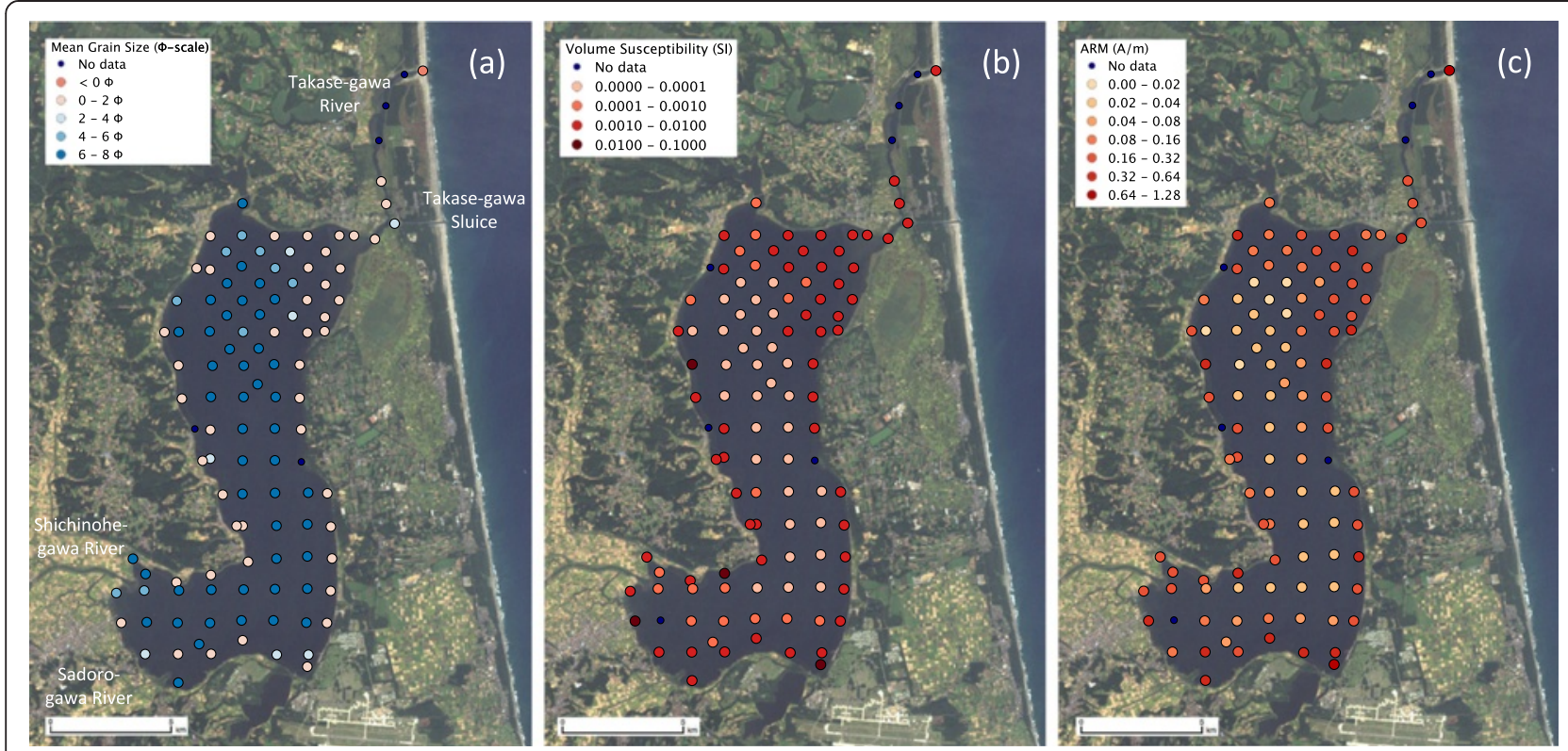

Fig. 2 Spatial patterns of the a phi scale mean grain size (Seto et al. 2012), b magnetic susceptibility, and c ARM intensity of bottom sediments. The base map is a LANDSAT 7 true color image (p107r032_ETM+ 2000-09-21)

\section{Methods}

We investigated the magnetic properties of bottom sediments with samples collected at Lake Ogawara in 2011 by Seto et al. (2012); these samples were collected with an Ekman-Birge bottom sampler at 112 sites at water depths of 0.75 to $24.7 \mathrm{~m}$, mostly on a $1-\mathrm{km}$ grid (Fig. 1). Details of water quality and sedimentological data will be reported elsewhere (Seto et al. in preparation). The bottom sediments were composed mainly of well-sorted fine to coarse sand at sites shallower than $6 \mathrm{~m}$ and of greenish black mud at deeper sites (Fig. 2a; Seto et al. 2012). We obtained samples for magnetic measurements by inserting plastic cubes (with one open face) with a $7-\mathrm{cm}^{3}$ volume into the sediments dredged at 105 sites.

We measured a low-field magnetic susceptibility of the cubic specimens soon after sample recovery by using an MS3 susceptibility meter with a MS1B sensor (Bartington Instruments) operating at a frequency of $0.47 \mathrm{kHz}$. After correction for the diamagnetic susceptibility of the plastic sample holder and instrument calibration by use of paramagnetic standard samples, the volume and mass susceptibilities were calculated. We also measured a susceptibility at $4.7 \mathrm{kHz}$, but detected no significant frequency dependence. On pilot specimens from 40 sites, we carried out a stepwise acquisition of ARM up to $100 \mathrm{mT}$ with a $0.1-\mathrm{mT}$ biasing field and alternating field (AF) demagnetization of the ARM. For other sites, ARM was imparted to specimens at $100 \mathrm{mT}$ AF. The ARM measurements were carried out in March 2012.

To investigate magnetic coercivity distributions, we also obtained isothermal remanence acquisition curves from eight selected samples in September 2012 and an additional five samples in April 2015. The IRM was progressively imparted up to $1.2 \mathrm{~T}$ by use of a pulse magnetizer (ASC, IM10-30). The IRM acquisition curves were analyzed by the method proposed by Kruiver et al. (2001) and Heslop et al. (2002). Measurements of ARM and IRM were made with a cryogenic magnetometer (Model 755R, 2G Enterprises), and the high-intensity IRM was measured with a spinner magnetometer (SMD88, Natsuhara Giken).

In addition to the non-destructive measurements, in April 2015, we performed thermal demagnetization of a composite three-axis IRM (Lowrie 1990) with selected samples. Magnetizing fields of $1.2,0.3$, and $0.08 \mathrm{~T}$ were applied to the sample along the three perpendicular axes. Then, the sample was subjected to stepwise thermal demagnetization up to $710^{\circ} \mathrm{C}$. During this experiment, we found that the acquired magnetic intensity was lower than that measured in 2012, particularly in mud samples from the deeper sites, thus suggesting that there may have been a loss of magnetic minerals during refrigerated storage for about 3 years. We therefore re-measured low-field magnetic susceptibility and ARM for samples from all sites in April and May 2015.

\section{Results and discussion}

The spatial distributions of magnetic susceptibility and ARM intensity data obtained at the peak AF of $100 \mathrm{mT}$ (Fig. 2b, c) showed higher values along the lakeshore at water depths less than $5 \mathrm{~m}$, and this area included the sites around the mouth of the Shichinohe-gawa and 
Sadoro-gawa rivers in the southwest part of the lake and the sites near the Takase-gawa River in the northeast part. The bottom sediments at these sites are dominated by medium sands (Fig. 2a), which suggests that magnetic minerals of detrital origin were transported into the lake both from the watershed to the southwest and by erosion of the sandbar on the Pacific coast near the mouth of the Takase-gawa River.

The results of stepwise acquisition and progressive AF demagnetization of ARM (Fig. 3) showed several patterns related to the location of samples in the basin. Sites near the mouth of the Shichinohe-gawa River yielded ARM acquisition curves mostly saturated above $60 \mathrm{mT}$ with a median destructive field (MDF) at about $20 \mathrm{mT}$ (Fig. 3a), but the curves for samples near the Sadoro-gawa River mouth did not show saturation below $100 \mathrm{mT}$, with the exception of the sample from site 110, for which the curves were similar to those of sediments from the Shichinohe-gawa region (dotted lines in Fig. 3b).

The shallow sites in the northeast part of the lake also showed the presence of a higher coercivity fraction, particularly in the Takase-gawa River and around its mouth (sites 1, 4, and 6 in Fig. 1; dotted lines in Fig. 3c). Other shallow-water sites close to the lakeshore were characterized by ARM with very low coercivity (Fig. 3d).

The ARM acquisition curves of clayey and silty sediments from sites at water depths greater than $10 \mathrm{~m}$ were mostly saturated above $60 \mathrm{mT}$ (Fig. 3e, f), although two sites near the Takase-gawa River mouth (sites 19 and 29 in Fig. 1; dotted lines in Fig. 3e) showed hard coercivities similar to those of samples from the northeast of the lake (Fig. 3c). Note that the MDFs of samples from 10 to $17 \mathrm{~m}$ water depth were less than $24 \mathrm{mT}$, but those from 17 to $24 \mathrm{~m}$ water depth were $25-28 \mathrm{mT}$.

As suggested by Fig. 2, magnetic concentration parameters in the lake sediments decreased with increasing water depth (Fig. 4). The decrease was most marked at water depths from 10 to $16 \mathrm{~m}$ in areas corresponding to the distribution of the greenish black mud. However, although magnetic susceptibility was persistently low below $16 \mathrm{~m}$ water depth, the ARM measured in 2012 increased slightly from about 16 to $25 \mathrm{~m}$. In the results of IRM acquisition experiments for selected samples (Fig. 5), the normalized acquisition curves showed that

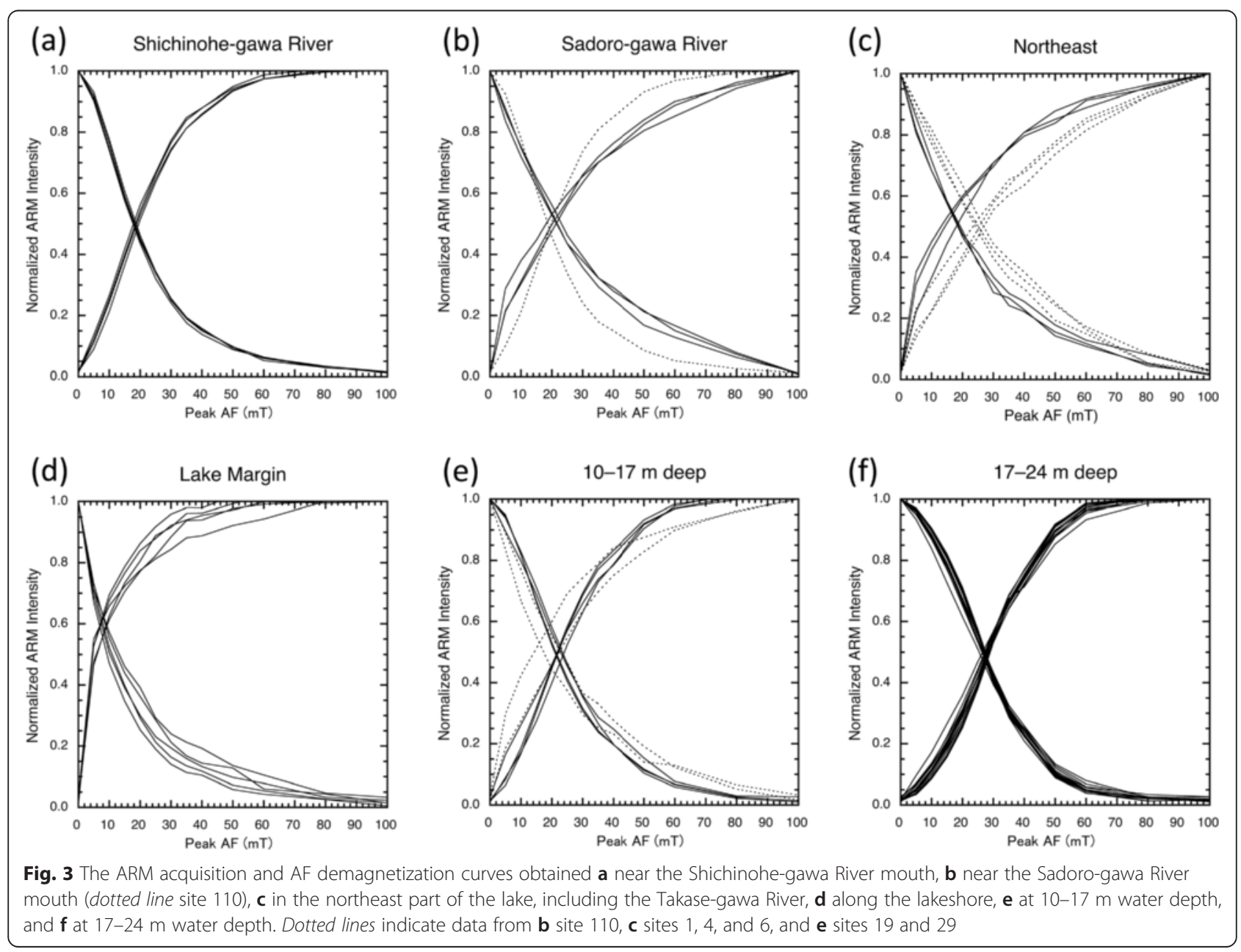




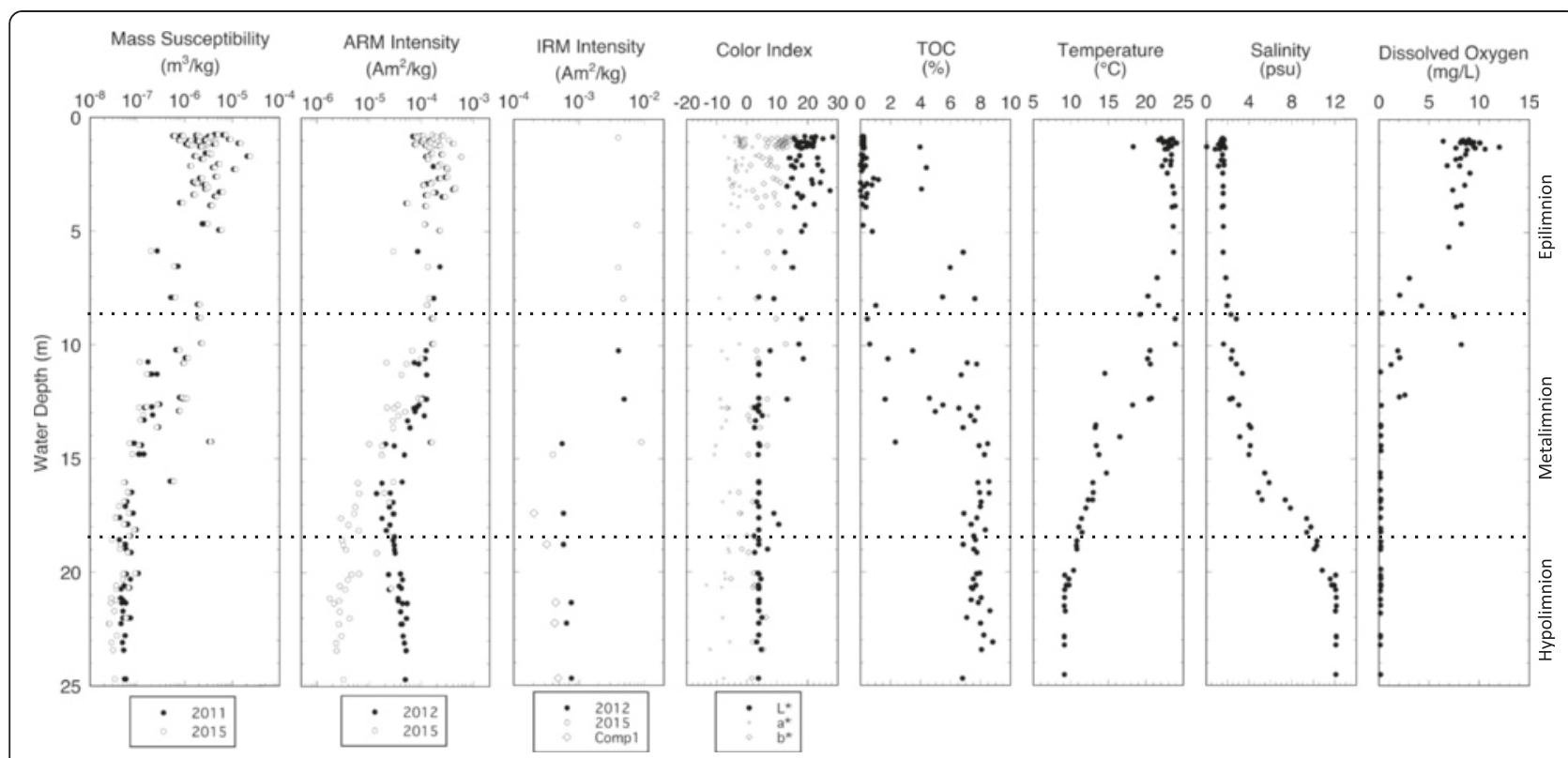

Fig. 4 Plots of magnetic susceptibility (measured in 2011 and 2015), ARM intensity at an 100 mT AF and 0.1 mT biasing field (measured in 2012 and 2015), and IRM intensity at 1.2 T (measured in 2012 and 2015) versus water depth. Intensity of the principal component with a narrow coercivity range at around $40 \mathrm{mT}$ (Comp 1) is shown in the IRM panel. Also shown are color index values and TOC contents of the sediments, bottom water temperatures, salinity, and dissolved oxygen contents at the sampling sites (Seto et al. 2012). Based on the water temperature and salinity, the water column has been divided (dotted lines) into the epilimnion (0-8 m), metalimnion (8-18 m), and hypolimnion (deeper than $18 \mathrm{~m}$ )
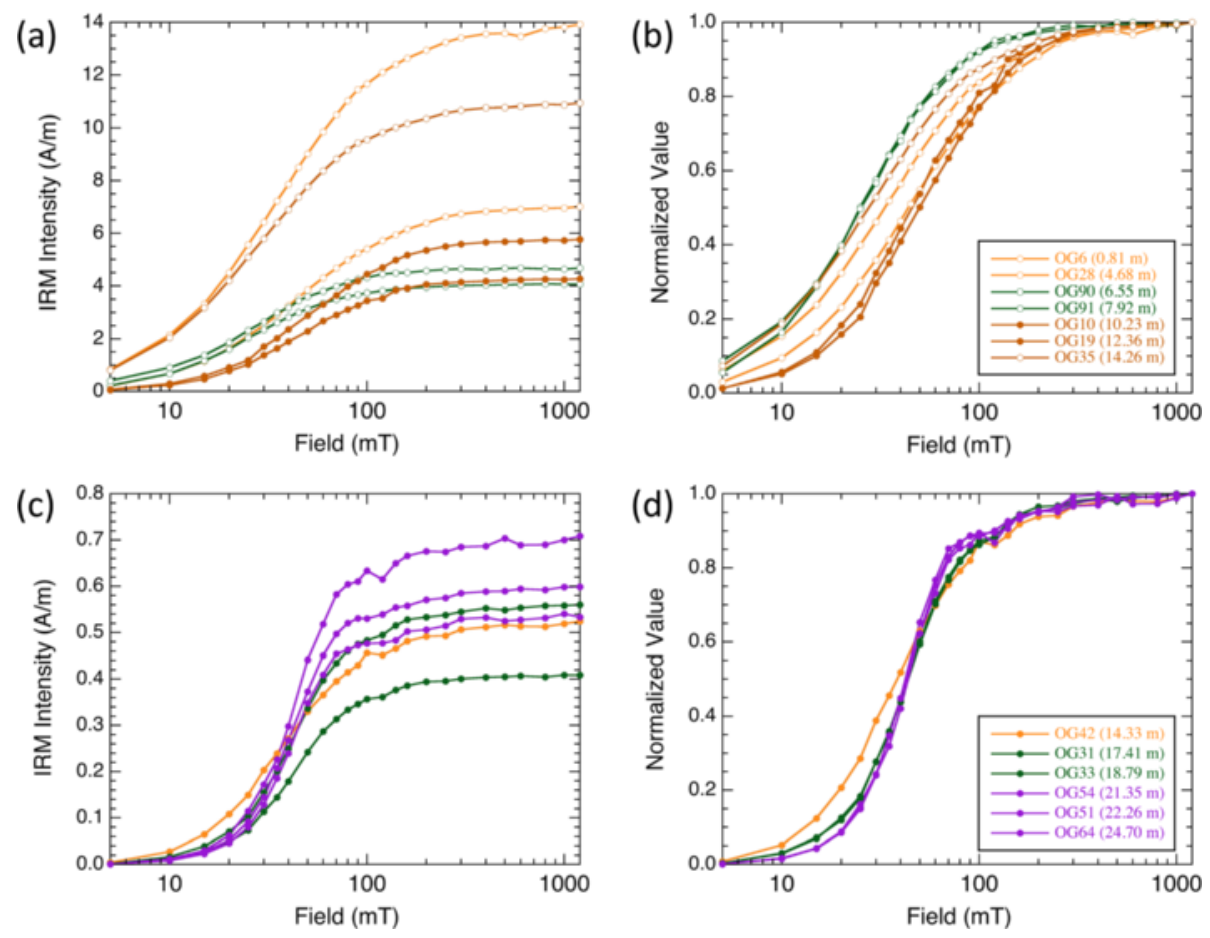

Fig. 5 Raw and normalized IRM acquisition curves for selected samples from $\mathbf{a}, \mathbf{b}$ shallow sites and $\mathbf{c}$, $\mathbf{d}$ deep sites. Closed and open dots represent data obtained in 2012 and 2015, respectively 
samples from sites at greater water depths (17-25 m) had narrower coercivity ranges than samples from shallower sites (less than $14 \mathrm{~m}$ water depth) measured in 2012. The gradient acquisition plots (Fig. 6; Kruiver et al. 2001) confirmed the presence of a component with a narrow coercivity range, around $40 \mathrm{mT}$, for which the intensity increased with water depth (Fig. 4). It is likely that this component corresponds to a downward increase of carriers of ARM below $16 \mathrm{~m}$ water depth.

As previously mentioned, the magnetic concentration parameters measured in 2015 were lower than the initial measurements. Magnetic susceptibilities and ARM intensities at sites shallower than $10 \mathrm{~m}$ water depth were reasonably consistent before and after the storage period, but both parameters in mud samples decreased considerably with water depth, particularly below $16 \mathrm{~m}$ (Fig. 4). The ARM intensities measured in 2015 were about 1 order of magnitude lower than those obtained in 2012, and greater loss was observed at deeper sites. Comparison of ARM and IRM properties measured in 2012 and 2015 for samples from site 51 (Fig. 7) suggests that the coercivity distribution broadened and softened during the 3 years the samples were stored. The decrease of magnetic concentration was likely caused by the loss of ARM carriers, which were initially characterized by a narrow coercivity range around $40 \mathrm{mT}$.

Water quality observations in the summer of 2011 (Fig. 4; Seto et al. 2012) clearly showed a thermocline and halocline from 8 to $18 \mathrm{~m}$ water depth. Thus, Seto et al. (2012) identified an epilimnion (0-8 m), metalimnion $(8-18 \mathrm{~m})$, and hypolimnion (deeper than $18 \mathrm{~m}$ ) in Lake Ogawara. Waters of the metalimnion and hypolimnion were anoxic to euxinic, and there was a downward decrease of susceptibility and ARM in the metalimnion, where dissolved oxygen was depleted (Fig. 4). The total organic carbon (TOC) contents of bottom sediments at water depths greater than $5 \mathrm{~m}$ were generally very high (4 to $9 \%$ ). We propose, therefore, that the decrease of magnetic concentration parameters with increasing water depth represents the loss of magnetic minerals through diagenetic dissolution under reductive conditions.

Depletion of magnetic oxides and the formation of authigenic iron sulfide associated with reductive diagenesis have been widely observed in association with down-core variations of the magnetic properties of hemipelagic and coastal marine sediments (e.g., Karlin 1990; Bloemendal et al. 1993; Liu et al. 2004; Rowan et al. 2009). Similar modifications of magnetic properties have been reported in studies of core samples from lake sediments in various regions (e.g., Anderson and Rippey 1988; Snowball 1993; Nowaczyk et al. 2001). The variations of magnetic properties of the bottom sediments with water depth in Lake Ogawara (Fig. 4) represent a profile analogous to such down-core variations. We suggest that diagenetic loss of magnetic minerals has occurred in the surficial sediments on the lake floor.

Rapid loss of magnetization during storage has been reported for organic-rich lake sediment cores (Oldfield et al. 1992) and for anoxic marine sediments (Richter et al. 1999; Roberts et al. 1999; Yamazaki et al. 2000). Such modifications of magnetic properties are known as "storage diagenesis" (Oldfield et al. 1992). As proposed by the studies cited above, the loss of magnetic material in our samples might reflect dissolution of fine-grained magnetite or decay of a metastable iron-sulfide such as greigite.
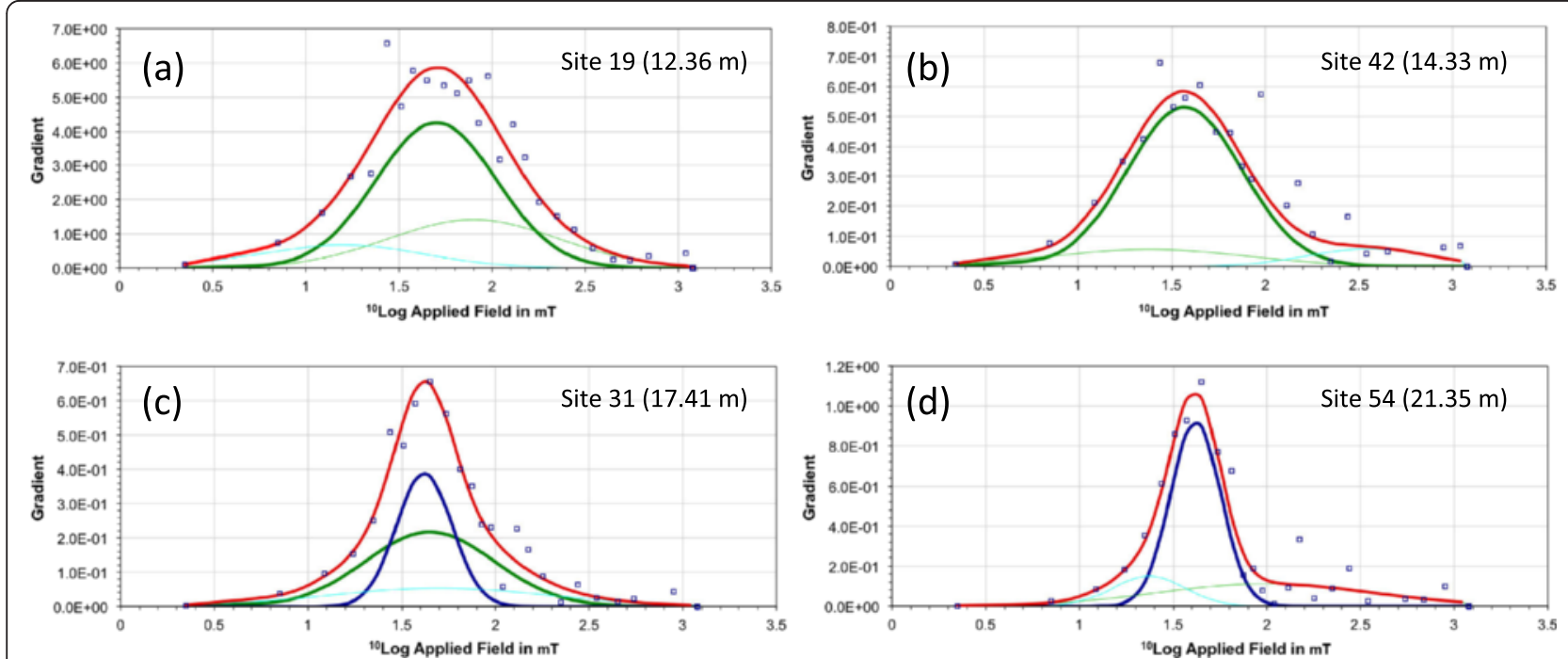

Fig. 6 Representative examples of gradient acquisition plots. Red lines show the sum of all components, and green and blue lines show abundant components in samples from a Site 19 at 12.36 m, b Site 42 at 14.33 m, c Site 31 at 17.41 m, and d Site 54 at 21.35 m water depth 

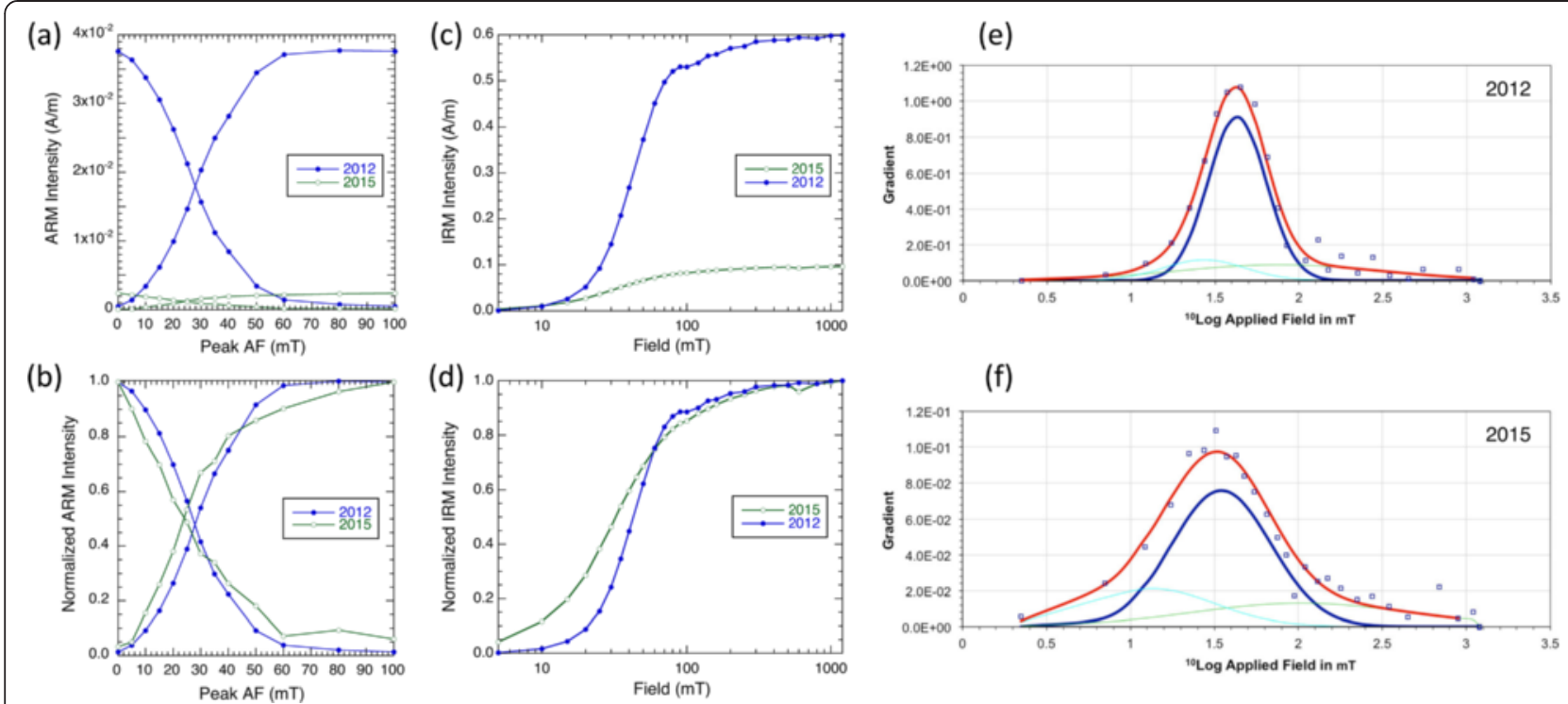

(f)

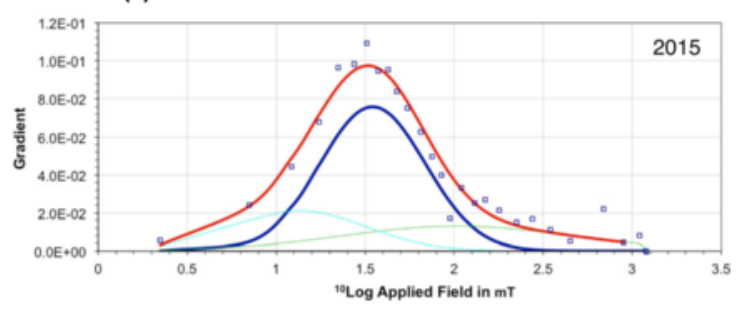

Fig. 7 Comparison of 2012 and 2015 a raw and $\mathbf{b}$ normalized ARM acquisition and AF demagnetization curves, c raw and $\mathbf{d}$ normalized IRM acquisition curves, and $\mathbf{e}, \mathbf{f}$ gradient acquisition plots for a sample from site 51 (22.26 m water depth)
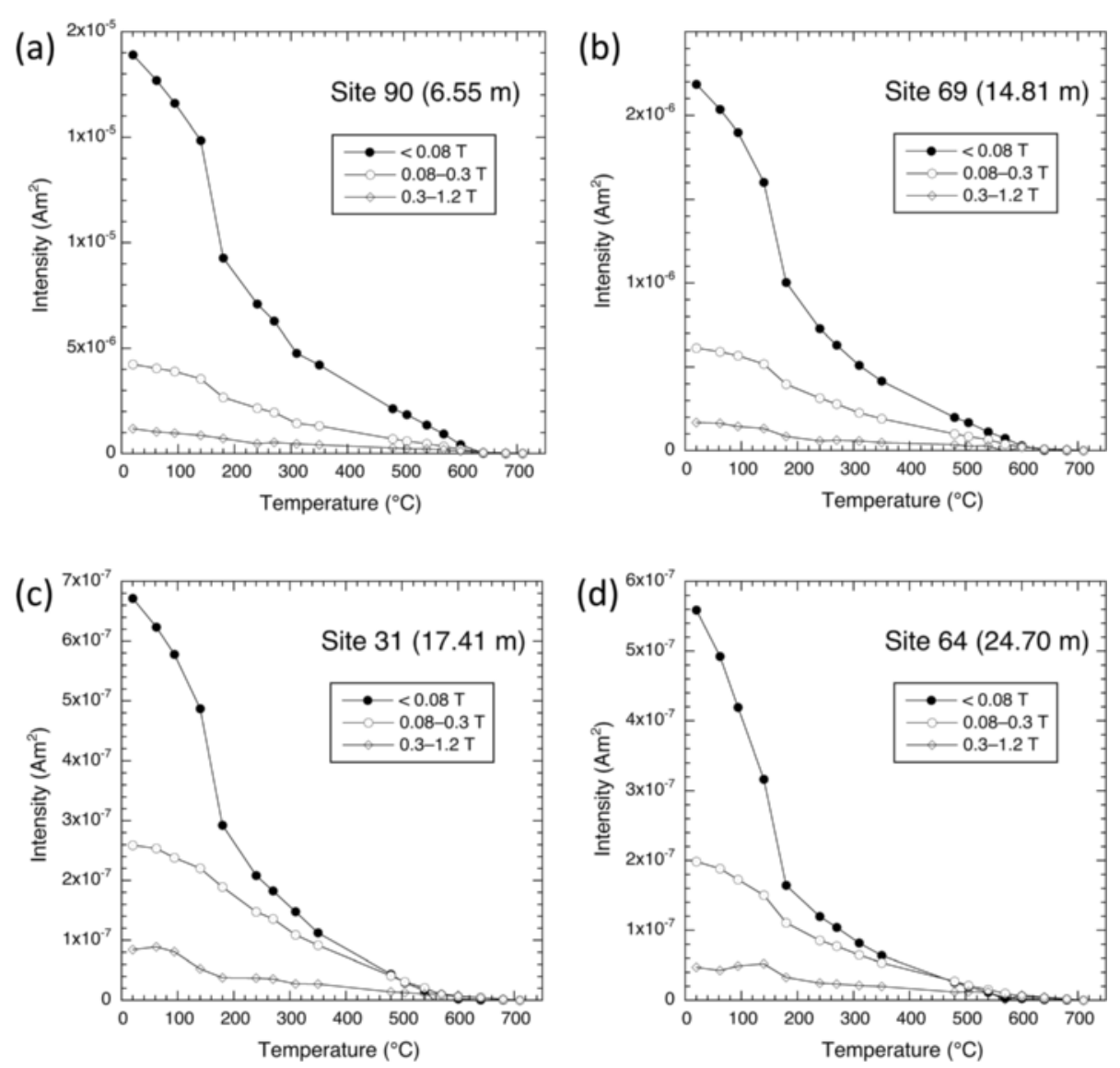

Fig. 8 Thermal demagnetization curves for the three-axis IRM obtained in 2015 for samples from a Site 90 at 6.55 m, b Site 69 at $14.81 \mathrm{~m}, \mathbf{c}$ Site 31 at $17.41 \mathrm{~m}$, and $\mathbf{d}$ Site 64 at $24.70 \mathrm{~m}$ water depth 
Examples of thermal demagnetization curves of threeaxis IRM measured in 2015 on four samples from Lake Ogawara after 3 years of storage (Fig. 8) showed unblocking of soft and medium IRM at temperatures around $160{ }^{\circ} \mathrm{C}$. This drop of intensity may represent decay of metastable magnetic minerals that remained after storage diagenesis. The IRM of the four samples was almost entirely removed at $570-600{ }^{\circ} \mathrm{C}$, which is suggestive of the presence of magnetite. The similarity of the thermomagnetic curves for the four samples implies that after storage diagenesis, the magnetic mineral assemblages of the samples from deeper sites changed to resemble those of the shallower sites, which were scarcely affected by storage diagenesis. The mineral assemblage of the samples from shallow sites may represent the most common magnetic minerals in the basin, which are probably of detrital origin.

There are two possible explanations for the origin of the magnetic minerals that were ARM carriers at the deeper sites and lost by storage diagenesis. The water quality data (Fig. 4) revealed that hypolimnion water deeper than $18 \mathrm{~m}$ was characterized by high turbidity and high chlorophyll a concentrations (Fujiwara et al. 2003b; Seto et al. in preparation), which implies that fine-grained magnetic minerals might have been supplied in suspension in the hypolimnion water delivered from the Pacific Ocean. However, ARM acquisition and demagnetization curves for sediments from the deep sites (Fig. 3f) were different from those observed at the shallow sites around the Takase-gawa River (Fig. 3c). Thus, it is more plausible that authigenic formation of iron sulfide occurred in the deeper lake floor sediments, which are overlain by anoxic water with high salinity and high organic matter content. This assumption is consistent with the occurrence of greigite in Holocene lake sediments such as those in Loch Lomond (Snowball and Thompson 1990). It is difficult, however, to clarify the magnetic mineralogy of the ARM carriers from the available data because it has been affected by storage diagenesis, which suggests that freezing of samples immediately after recovery is crucial for future environmental magnetic studies of organic-rich sediments.

\section{Conclusions}

Our measurements of the magnetic susceptibility and ARM of dredged sediment samples from Lake Ogawara showed that medium sand samples at shallow littoral sites are characterized by high magnetic concentrations. The results of stepwise acquisition and demagnetization of ARM showed several patterns that possibly represent differences in the provenance of the sediments and different water depths. For the sites at water depths greater than $10 \mathrm{~m}$, where lake floor sediments consist of greenish black mud with very high TOC contents, the magnetic susceptibility and ARM decreased with increasing water depth, although the initial measurements in 2012 showed a slight increase in the ARM for water depths greater than $16 \mathrm{~m}$. The ARM carriers were characterized by a narrow coercivity range around $40 \mathrm{mT}$, but this component was considerably reduced after sample storage for about 3 years. Although it is not clear whether the ARM carriers were the result of authigenic formation of iron sulfide or the deposition of material suspended in the hypolimnion water, we suggest that the magnetic properties of the surficial sediments on the lake floor are controlled by both their location in the basin and the limnological stratification of the brackish lake water. However, we conclude that freezing of samples immediately after recovery to avoid the effects of storage diagenesis is crucial for future environmental magnetic studies of organic-rich sediments. The results of our study may provide an analog for down-core variations of magnetic parameters associated with modification of magnetic minerals during reductive diagenesis.

\section{Competing interests}

The authors declare that they have no competing interests.

\section{Authors' contributions}

$\mathrm{KS}, \mathrm{KY}$, and $\mathrm{HY}$ coordinated the survey of Lake Ogawara and participated in the fieldwork with $\mathrm{AN}, \mathrm{RN}$, and $\mathrm{AH}$. $\mathrm{AH}$ and $\mathrm{RN}$ did the magnetic analysis, and $\mathrm{AN}$ and $\mathrm{KS}$ did the chemical and sedimentological analysis. $\mathrm{AH}$ conceived the study and drafted the manuscript. All authors read and approved the final manuscript.

\section{Acknowledgements}

We thank Yuko Okazaki, Hiromi Nakashima, Mutsumi Akimitsu, Katsuya Gotanda, Megumi Saito, Takeshi Haraguchi, Yoshitsugu Shinozuka, and Junko Kitagawa for their enthusiastic support during the fieldwork in Lake Ogawara. We also thank two anonymous reviewers and the editor, Yuhji Yamamoto, for valuable comments to improve the manuscript. This work was supported in part by grants from the Japanese Ministry of Education, Culture, Sports, Science and Technology (KAKENHI Grant Nos. 15K05321, 21101002, and 26101002).

\section{Author details}

${ }^{1}$ Department of Environmental Systems, Doshisha University, Kyotanabe, Kyoto 610-0321, Japan. ${ }^{2}$ Research Center for Coastal Lagoon Environments, Shimane University, Matsue 690-8504, Japan. ${ }^{3}$ Museum of Natural and Environmental History, Shizuoka Prefecture, Shizuoka 420-8601, Japan. ${ }^{4}$ Naruto University of Education, Naruto 772-8502, Japan.

Received: 31 January 2015 Accepted: 14 October 2015 Published online: 23 October 2015

\section{References}

Anderson NJ, Rippey B (1988) Diagenesis of magnetic minerals in the recent sediments of a eutrophic lake. Limnol Oceanogr 33:1476-1492. doi:10.4319/lo.1988.33.6_part_2.1476

Bloemendal J, King JW, Hunt A, deMenocal PB, Hayashida A (1993) Origin of the sedimentary magnetic record at Ocean Drilling Program sites on the Owen Ridge, western Arabian Sea. J Geophys Res 98:4199-4219

Evans ME, Heller F (2003) Environmental magnetism: principles and applications of enviromagnetics. Academic, San Diego

Fujiwara H, Mizuno S, Takasugi S, Sugita H, Yaguchi J (2003a) Field research on salinity and water temperature distribution in Lake Ogawara. Res Rep Hachinohe National College of Technology 38:169-173

Fujiwara H, Takasugi S, Mizuno S, Yaguchi J, Sugita H (2003b) Field observation on chlorophyll — a and turbidity in Lake Ogawara. Res Rep Hachinohe National College of Technology 38:165-168 
Heslop D, Dekkers MJ, Kruiver PP, Van Oorschot IHM (2002) Analysis of isothermal remanent magnetisation acquisition curves using the expectation-maximisation algorithm. Geophys J Int 148:58-64

Inagaki T, Shinozuka Y, Yamada K, Yonenobu H, Hayashida A, Tsuchikawa S, Yoshida A, Hoshino Y, Gotanda K, Yasuda Y (2012) Rapid prediction of past climate condition from lake sediments by near-infrared (NIR) spectroscopy. Appl Spectrosc 66:673-679

Karlin R (1990) Magnetite diagenesis in marine sediments from the Oregon continental margin. J Geophys Res 95:4405-4419

Kruiver PP, Dekkers MJ, Heslop D (2001) Quantification of magnetic coercivity components by the analysis of acquisition curves of isothermal remanent magnetization. Earth Planet Sci Lett 189:269-276

Liu J, Zhu RX, Roberts AP, Li SQ, Chang JH (2004) High-resolution analysis of early diagenetic effects on magnetic minerals in post-middle-Holocene continental shelf sediments from the Korea Strait. J Geophys Res 109:B03103. doi:10.1029/ 2003JB002813

Liu Q, Roberts AP, Larrasoaña JC, Banerjee SK, Guyodo Y, Tauxe L, Oldfield F (2012) Environmental magnetism: principles and applications. Rev Geophys 50:RG4002. doi:10.1029/2012RG000393

Liu Q, Sun Y, Qiang X, Tada R, Hu P, Duan Z, Jiang Z, Liu J, Su K (2015) Characterizing magnetic mineral assemblages of surface sediments from major Asian dust sources and implications for the Chinese loess magnetism. Earth Planets Space 67:61. doi:10.1186/s40623-015-0237-8

Lowrie W (1990) Identification of ferromagnetic minerals in a rock by coercivity and unblocking temperature properties. Geophys Res Lett 17:159-162

Nowaczyk NR, Harwart S, Melles M (2001) Impact of early diagenesis and bulk particle grain size distribution on estimates of relative geomagnetic palaeointensity variations in sediments from Lama Lake, northern Central Siberia. Geophys J Int 145:300-306

Oldfield F, Darnley I, Yates G, France DE, Hilton J (1992) Storage diagenesis versus sulfide authigenesis: possible implications in environmental magnetism. J Paleolimnol 7:179-189

Richter C, Hayashida A, Guyodo Y, Valet J-P, Verosub KL (1999) Magnetic intensity loss and core diagenesis in long-core samples from the East Cortez Basin and the San Nicolas Basin (California Borderland). Earth Planets Space 51:329-336

Roberts AP, Stoner JS, Richter C (1999) Diagenetic magnetic enhancement of sapropels from the eastern Mediterranean Sea. Mar Geol 153:103-116

Rowan CJ, Roberts AP, Broadbent T (2009) Reductive diagenesis, magnetite dissolution, greigite growth and paleomagnetic smoothing in marine sediments: a new view. Earth Planet Sci Lett 277:223-235

Seto K, Nagashima A, Okazaki Y, Nakashima H, Akimitsu M, Yamada K, Yonenobu $Y$ (2012) The feature of aquatic environment and surface sediment in the Lake Ogawara, Aomori Prefecture, north Japan. Paper presented at the Japan Geoscience Union Meeting 2012, Makuhari, http://www2.jpgu.org/meeting/ 2012/html5/PDF/A-PE33/APE33-03_e.pdf, Accessed 26 Jan 2015

Snowball I (1993) Mineral magnetic properties of Holocene lake sediments and soils from the Kårsa valley, Lappland, Sweden, and their relevance to palaeoenvironmental reconstruction. Terra Nova 5:258-270. doi:10.1111/j.1365-3121.1993.tb00257.x

Snowball I, Thompson R (1990) A stable chemical remanence in Holocene sediments. J Geophys Res 95:4471-4479. doi:10.1029/JB095iB04p04471

Thompson R, Oldfield F (eds) (1986) Environmental magnetism. Allen and Unwin, London

Yamazaki T, Solheid PA, Frost GM (2000) Rock magnetism of sediments in the Angola-Namibia upwelling system with special reference to loss of magnetization after core recovery. Earth Planets Space 52:329-336

\section{Submit your manuscript to a SpringerOpen ${ }^{\odot}$ journal and benefit from:}

- Convenient online submission

- Rigorous peer review

- Immediate publication on acceptance

- Open access: articles freely available online

- High visibility within the field

- Retaining the copyright to your article

Submit your next manuscript at $>$ springeropen.com 